\title{
How to Persuade Government Officials to Grant Interviews and Share Information for Your Research
}

\author{
Irene S. Wu, chair, Working Group on Practicing Politics; U.S. Federal Communications Commission; and Georgetown University \\ Bojan Savić, University of Kent, Brussels School of International Studies
}

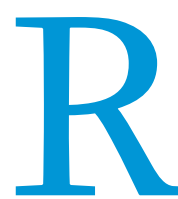

ick Farmer's article focuses on ways in which academic political scientists can influence policymakers. At the Toronto meeting of the Working Group on Practicing Politics, government political scientists also recognized that academics often are frustrated by the process of getting information from the government and cooperation from officials.

To address this issue, Bojan Savić, lecturer at the University of Kent, Brussels School of International Studies, surveyed 30 of his academic colleagues ( 16 male, 14 female) to identify their greatest frustrations in working with governments. These researchers primarily worked with European Union governments, NATO, the European Commission, and the European Parliament. Table 1 contains the distilled complaints drawn from the interviews.

The most common complaint cited was overemphasis of the putative theory/practice divide by government and intergovernmental organization (IGO) representatives, which vary from denial to academics that they can fully grasp policy-related aspects of a problem to the criticism that they often fail to understand the "political sensitivity of the moment" and remarks that "Yes, theory may say that, but in practice..." Other complaints noted that government/IGO representatives often tend to promote the selfimage of actors central to the issue on whom the solution or escalation of the problem depends or who possess the capacity to generate opportunities, benefits, and costs. Especially regarding interviews, government and IGO representatives tend to be concerned that their statements, even if left anonymous, will be misrepresented or misused for the purpose of an academic argument that may allegedly distort their "evaluative meaning" or "truth value." All respondents, however, acknowledged that this concern was never stated explicitly by government/IGO representatives, but was rather a concern perceived by the academics themselves. As well, it can often be unclear to academics who are involved in government or IGO-funded research what government/IGO representatives want them to base their policy analysis on-often, these representatives do not expect "neutral" research, but would rather see national or organizational values

Irene $\mathbf{S} . \mathbf{W u}$ is a research director in the international section of the Federal Communications Commission, although the views expressed in this article are her own and not of the FCC. She is also an adjunct professor at Georgetown University. She can be reached atireneswu@yahoo.com.

Bojan Savić teaches quantitative methods of analysis in international studies at the University of Kent (Brussels School of International Studies), where he is also completing a Ph.D. on the application of game theory to the study of international military alliances and, more specifically, NATO civilian and military transformation in the post-Cold War period. He also teaches at the Vesalius College of the Vrije Universiteit Brussel. He can be reached atbs214@kent.ac.uk. explicitly embedded in the work. Furthermore, respondents stated that they often receive mixed input from different ranks of government/IGO representatives with respect to the scholarly independence of the work being done for a specific government or IGO.

In consultation with Savić, these complaints were translated into six questions, which I posed to three other members of the working group who have spent a significant part of their careers working in the government. All are Ph.D. political scientists with current university affiliations: Carol Atkinson, former U.S. military intelligence analyst, now at Vanderbilt University; Jorge Heine, Chile's former ambassador to South Africa and India, now at the Balsillie School of International Affairs; and John Wood, City Councilman, Guthrie, Oklahoma, also at Rose College. In early December, I e-mailed the questions to them in advance and asked them to spend 20 minutes on the phone with me answering the questions. Although the three interviewees had widely diverse academic and government experience, their suggestions converged remarkably. First, Heine and Wood observed that while many government officials have difficulty seeing the relevance of theory to their daily routine, in fact, theory can provide guidance on which questions are important to ask in any given crisis. Atkinson notes, however, the extreme importance of theory being clearly grounded in empirical evidence-current or historical. Second, government officials are more than happy to give interviews and share information when a researcher can explain the goal of his or her research and its likely impact on the world. It is also very important that the official feels comfortable with the researcher-his or her agenda, credentials, level of knowledge and preparation, and personal references. Finally, all three interviewees discuss their views on the role of independent research as compared to partisan analysis and the necessity of predictions in research to make such work of interest to policymakers. What follows are highlights from these interviews.

1. Why do government officials frequently believe that "Yes, theory may say that, but in practice ..."? What aspects of policymaking do you find academics frequently fail to understand?

2. When and how have academic arguments been valuable to your policy work? When are they detrimental, and how?

Heine: In government, you are always putting out fires and moving from one crisis to the next-in other words, dealing with the day-to-day agenda. Theory seems to deal with mid- and longterm trends. When you are in high-level positions in government, you find it very difficult to look at medium to long term. The 
Table 1

\section{Researchers' Frustrations Working with Government Officials}

COMPLAINT/PROBLEM

\begin{tabular}{lc}
\hline Overemphasis of the putative theory/practice divide by government/IGO representatives & 19 \\
\hline Coming inadequately prepared to interviews/providing inadequate information & 12 \\
\hline Self-image of the "issue-owner" & 11 \\
\hline Lack of will to learn academic arguments in a given debate & 10 \\
\hline Exaggerated political correctness/professional discretion (confidentiality) & 10 \\
\hline Assumptions that academics have a potentially dishonest a priori agenda & 9 \\
\hline Unclear expectations from academics & 7 \\
\hline Confusion between "gossiping" and providing valuable information and insight & 6 \\
\hline Overly high expectations from academics & 6 \\
\hline Lack of political correctness & 4 \\
\hline Total complaints/problems & 94 \\
\hline
\end{tabular}

Note. IGO: Intergovernmental organization.

dismiss these candidates as talking mumbo jumbo. Sometime I talk that way myself, which might hinder my ability to talk to other councilmen, or they might think I'm arrogant.

3. What motivates you to provide information to researchers? What warning signs suggest you should not provide the information requested?

4. Why do you trust some interviewers with your views, and why are you concerned with other interviewers that your views may be misrepresented?

Wood: You have to be careful about what you provide. Interviews can open you up to law-

urgent tends to crowd out what is important.... Theory is seen as somewhat philosophical and aesthetically pleasing, but not necessarily as something that provides answers to daily imperatives. My own take is that [this approach] is wrong. Theory provides tools to understand many challenges, their underlying causes, and the direction they are going. When I was in office, in [Chile's] foreign service, serving as ambassador to South Africa and India, I found theoretical instruments very useful to understand my main tasks. For example, the apparent chaos of the South African civil service in the first year of the Mandela presidency had to be set within the dynamics of democratic transitions. From such a perspective, enormous opportunities, unique to such periods, arose. The creation of the South African Truth and Reconciliation Commission, in which I was involved, and which ended up being one of the great accomplishments of Mandela's government, is one such case.

Atkinson: Theory may ... be at a level that doesn't help us with policy questions or with problems today which are very specific. I've heard Hillary Clinton say in testimony in Congress that we need to use our smart power. That is a concept that comes from academia. What does it mean to someone working on everyday issues? ... If you are a politician, it may be useful rhetorically, but at the working level, it may not be as useful.... Policymaking is about solving problems; academics are more focused on broad concepts, achieving tenure, and publishing in academic journals, which takes a long time due to lengthy review processes.

Wood: Academic arguments in my work are both good and bad.... The academic side brings information, allows you to understand what questions to ask in a lot of ways.... How can academic arguments be detrimental?... We are hiring a city manager and I have an ideal sense of what a city manager should be. The reality is [that] I'm butting head with other city councilmen, the mayor, and human resources. What they want is not this ideal-they don't want to pay anything for city manager. They want someone to fix everything, someone with local knowledge, not necessarily someone with managerial experience. In these interviews, some interviewees will use a lot of technical management language. Some suits; there are some things which are private. If I go to an executive session and we talk about legal matters, I can be prosecuted for divulging information. Also, what you've said is under a microscope-newspapers can exaggerate and put it out of context. If there's a warning sign out there, if someone is kind of emotional about something and you try to debate with that person, you can get in trouble there. That is [a situation when] your words can be misconstrued. That's why you find out politicians won't fill out a survey [or are] concerned about what's the intent, what I say will be used against me out of context.

Atkinson: My experience in government was as active duty military. For the vast majority of the time, I worked in intelligence analysis. It would not be in my realm to talk with a researcher or give an interview.... [However, when reviewing written research], when evaluating material, you compare academic research with what you know and see if it matches with facts as you know them. If it fills in a gap you don't know or challenges what you do know, that is important.... When I was in the policy world, the works that were useful ... were those that focused on a problem that we might be dealing with. They may use theory and data and analyze data, but, in the end, they came back to the problem. [The researcher says] "based on what I saw, this is an aspect of the problem I can provide further information on, or I have a solution that is more likely to work."

Heine: My experience is that it is amazing how much info [government officials] will provide if you lay out clearly what you are trying to achieve, if you give indications that show you know what you are talking about, and if you have the right credentials. Who makes the contact is critical. A cold call will often end up with a cold answer. If you approach the informant through a government colleague, a common acquaintance, someone informants trust, the difference is enormous. Second, it is important the person has the right credentials. If the interviewer has the proper training and background as a social scientist, that is reassuring. Third, one can see from the first questions whether this is someone serious or not. If a person has not prepared himself, I will quickly realize I am wasting my time. Talking to people must be 
the last stage of research, after having gone through much of the available documentary evidence, since it is much more inefficient to obtain information verbally than from written material.

\section{What do you view as the role of research in policymaking? When do you require independent research and when do you require partisan or activist research?}

Heine: Let's start with the last part. One requires partisan or activist research when one [has] embarked on some significant cause one wants to support and move forward. This can be a political campaign, a broader cause in which one needs strong, welldeveloped arguments that can be compressed in bullet points or 3o-second sound bites on the radio or TV, with passion and conviction. On the other hand, when one is engaged in government policy, one is better helped by nonpartisan research that lays out all the elements on the table and thus helps you make a better judgment as to which direction to take. If you are engaged in an advocacy project, you can very well rely on partisan research-the sort of thing that think tanks aligned with different causes will provide you with. If you are a government official engaged in major policy evaluation or policy project, then you are much better off with nonpartisan research.

Atkinson: I never looked at partisan or activist research. [When I worked in government], I would go home at night and read the history of Soviet Union, I would read about some of the samizdat literature, the privately published, dissident literature.... After I was in the Middle East, after Desert Storm in 1991, I would read at home things kind of from the academic line, but not political science research per se, such as T. E. Lawrence, historical accounts of the evolution of politics, and evolution of tribes. [This was] much more history-oriented-this is where we are today, how did this come about?

Wood: [At the city level], we get information from municipal and from the city manager. I'm worried more about what their agenda is rather than about partisan questions; it is more a kind of a personality thing. That's why at city manager level, [the Guthrie City Council] want a Guthrie person, while I just want a good, confident manager. They want a local person because they want to trust him Maybe it's a southern question, a traditionalist mentality, also, a little nepotistic.... I'm atypical in that way, because I have a doctorate, so I think about where my information comes from. I don't think people at this level think about partisanship or objectivity; they look at whether it is familiar or not.

\section{How important is it to you that research contain policy recommen- dations or predictions?}

Heine: John F. Kennedy famously said, "Give me a one-armed economist," because he was tired of his advisors telling him, "On the one hand, but on the other ..." At some point, you need to come down on one side.... If you are engaged in a significant analysis of government policy and want to make any changes, you need to evaluate all the elements. While at the end of the day, you want the researcher to come up with specific recommendations, the process, the data, and the evidence [that] he or she has relied on to come up with a conclusion is as important for the policymaker as the specific policy recommendation itself. So I will take a middle-of-the road course here. It is important for policyoriented research to come up with recommendations, but as significant as the recommendation itself is the causal chain that led to it. The latter should follow smoothly from that causal chain, making evident that those recommendations have an objective basis and are not simply a subjective preference. The same goes for predictions of likely policy outcomes to emerge from particular programs. To be involved in politics at the highest levels is to live with extreme uncertainty. Reliable, well-grounded predictions that allow ministers or other high-ranking policymakers to reduce that level of uncertainty in terms of the outcome of certain policies are thus at a premium.

Wood: As a city councilman, [policy recommendations and predictions are] actually a good thing. As city councilmen, we look at budgets; we make a lot of decisions every other week on how much we spend. Seldom do we have any information which is predictive. Many decisions are made on the fly-we don't have the time to understand what the implications are. The cyclical nature of politics makes it so hard to think beyond four to five years. I might not be around in four to five years. I have four years to do what I have to do, but a lot of things have a time scale of 10 to 20 years.... People are not looking for the predictive element, they are looking for the cost-effective, the technically proficient, that's not going to get their constituents upset with them.... For example, for big purchases, a $\$ 15$ million water plant, if we had a policy paper on implications of how we could pay for that, we might end up doing a fee or city tax. What's the best method for paying for the water plant?

\section{CONCLUSION}

To conclude, from the point of view of political scientists who have worked in government, academic research-both theory and data-can make major contributions to policymaking and governance. To persuade government officials to cooperate with research, however, researchers need to convey clearly how their work is relevant to the problems of today and tomorrow, and to invest in professional relationships with relevant government officials. As Heine argues,

We live in the age of information.... Therefore, successful policymakers will have to rely more on research. And researchers will have to realize that if they want their research to be deployed by policymakers, they will have to do what's needed to convey it in as accessible and user-friendly fashion as possible. Three hundred-page reports written in jargon-filled, impenetrable prose, loaded with undecipherable tables, will no longer do. You need to make your research more user-friendly to policymakers and their advisors if you want to get your points across.

If the culture and values of the two communities can be bridged, the benefits to all should be enormous. 


\section{American Political Science Association}

\section{Centennial Center for Political Science \& Public Affairs Research Opportunities in Washington, D.C.}
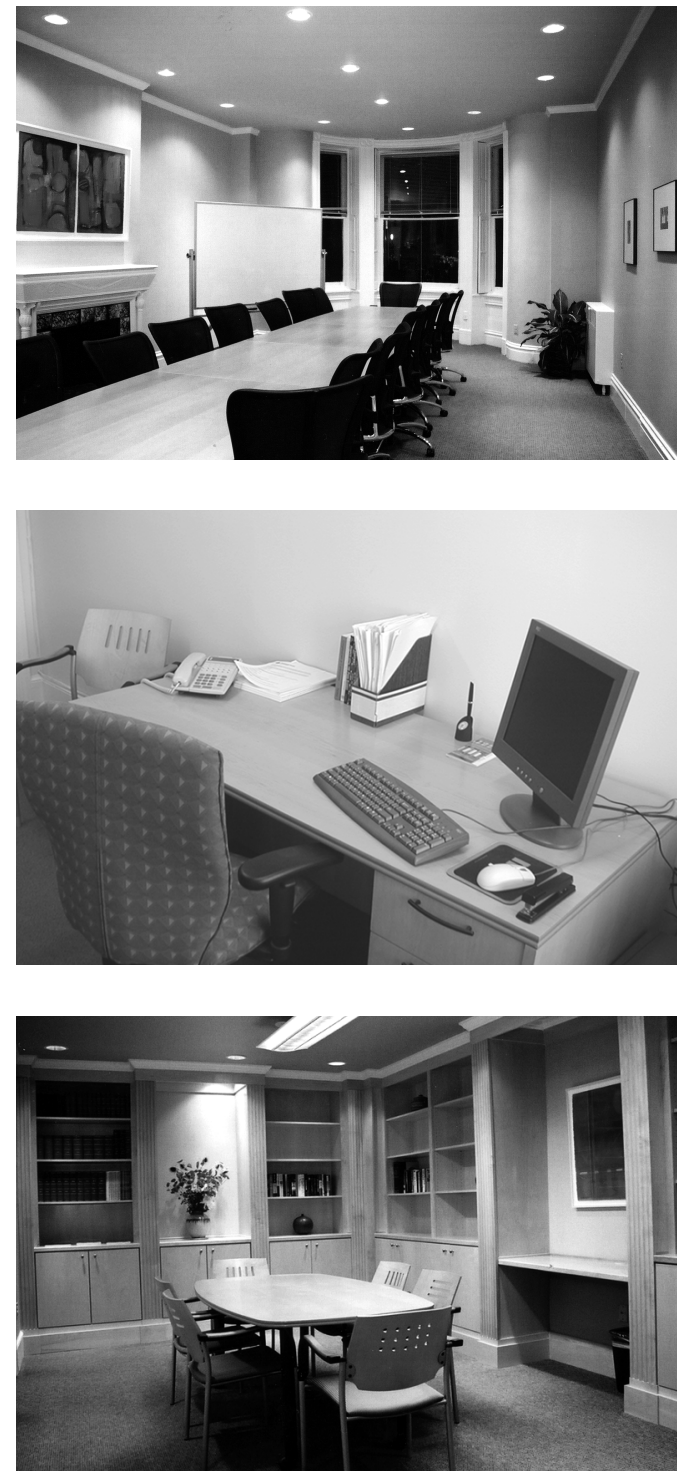

lenjoyed my stay in Washington D.C. immensely, and the high quality facilities and friendly staff at the Centennial Center made it a great base from which to conduct my fieldwork. I found the facilities to be well located making it easy to travel to my interviews and use the National Security Archive at GWU. Coming to Washington as an international scholar, I found it helpful when securing key interviews to have the support of such a respected organization.

-Emma Briant, University of Glasgow

Created in celebration of the American Political Science Association centennial, the Centennial Center for Political Science and Public Affairs encourages research, writing, and collaboration among scholars working within the discipline.

The Center, located in Association headquarters in D.C., assists scholars from the United States and abroad whose research and teaching could benefit from a stay in and access to the incomparable resources in the nation's capital. The Center has space for ten visiting scholars for extended periods of time ranging from a few weeks to a year.

The Center features:

- personal work space

- computer, high-speed internet, and wireless

- personal phone, fax, and printing

- flexible scheduling for long and short stays

- convenient downtown location, metro accessible

- meeting and conference room facilities

- reference library

- night and weekend access

- community of scholars

- access to: U.S. government, Library of Congress, National Archives, World Bank, International Monetary Fund, USAID, national party headquarters, embassies from around the world, Organization of American States, etc.

\section{Funding Opportunities}

As a result of generous contributions by members and friends, APSA developed endowments for grant programs that may support stays at the Centennial Center.

Applications may be submitted throughout the year and will be reviewed on a rolling basis. If you would like to be considered for funding, it is recommended that you apply before February 28. 